\title{
Perancangan Manajemen Insiden pada Layanan Teknologi Informasi Inventory Menggunakan Framework ITIL Versi3 (Studi Kasus : PT. Genta Semar Mandiri Semarang)
}

\author{
Nadya Azizah ${ }^{1}$, Yupie Kusumawati ${ }^{2}$, Ramadhan Rakhmat Sani ${ }^{3}$ \\ Fakultas Ilmu Komputer, Universitas Dian Nuswantoro Semarang \\ Jl.Imam Bonjol No.207 Semarang, telp. (024) 3569196 \\ e-mail: 'nadyaazizah15@yahoo.co.id, ${ }^{2}$ yupie@dsn.dinus.ac.id, ${ }^{3}$ ramadhan_rs@dsn.dinus.ac.id
}

Diterima: 24 April 2020; Direvisi: 30 Mei 2020; Disetujui: 31 Mei 2020

\begin{abstract}
Abstrak
Teknologi informasi digunakan oleh PT. Genta Semar Mandiri untuk mempermudah proses bisnis inventory. Namun pada kenyataanya masih sering terjadi insiden yang menghambat proses bisnis inventory. Insiden yang sering terjadi adalah aplikasi sering error, part number tidak terintegrasi dengan sistem, dan basis data overload. Selama ini insiden tersebut tidak dikelola dengan baik, hal ini disebabkan karena tidak adanya divisi yang khusus menangani insiden TI, serta belum dibuatnya SOP yang digunakan sebagai acuan menangani insiden TI. Penelitian ini bertujuan untuk mendapatkan hasil kesenjangan antara kondisi eksisting dengan kondisi ideal proses manajemen insiden pada PT. Genta Semar Mandiri serta mendapatkan SOP yang di perlukan dalam manajemen insiden. Penelitian ini menggunakan Framework ITIL versi 3 dalam merancang kerangka kerja dalam manajemen layanan insiden. Penelitian menunjukkan adanya beberapa perbedaan antara kondisi eksisting dengan kondisi ideal yaitu tidak adanya divisi khusus yang menangani manajamen layanan insiden, serta tidak adanya service desk yang bertugas sebagai pintu gerbang layanan insiden. Sehingga dihasilkan beberapa perubahan yaitu penambahan struktur organisasi pada perusahaan, SOP, serta form yang diperlukan pada penanganan manajemen layanan insiden berdasarkan framework ITIL versi 3.
\end{abstract}

Kata kunci: Manajemen insiden, itil versi 3, sop, pt. genta semar mandiri

\begin{abstract}
Information technology is used by PT. Genta Semar Mandiri to facilitate the inventory business process. However, in fact there are still often incidents that hamper the inventory business process. Common incidents are frequent application errors, part numbers not integrated with the system, and database overload. So far, the incident have not been managed properly, this is due to the absence of a division that specifically handles IT incidents, and the SOP has not been made as a reference for handling IT incidents. This study aims to obtain the results of the gap between the existing conditions with the ideal conditions of the incident management process at PT. Genta Semar Mandiri and get the SOPs needed in incident management. This study uses ITIL Framework version 3 in designing a framework in incident service management. Research show that there are some differences between existing conditions and ideal conditions, namely the absence of a special division that manages incident service management, and the absence of service desk that serves as a gateway for incident services. So that resulted in several changes, namely the addition of the
\end{abstract}


organizational structure of the company, SOP, and the forms needed in handling incident management services based on the ITIL framework version 3.

Keywords: Incident management, itil version 3, sop, pt. genta semar mandiri

\section{PENDAHULUAN}

Bersamaan dengan perkembangan teknologi informasi pada era modern seperti sekarang ini mengakibatkan kebutuhan akan informasi semakin penting.Salah satu alasan utama memanfaatkan teknologi informasi adalah agar fungsi prosedur bisnis dan teknologi yang berjalan dalam organisasi semakin maju. Namun ada yang menjadi masalah pada saat menerapkan teknologi informasi yaitu tentang cara menyelaraskan dan mengintegrasikan strategi teknologi dan bisnis. Salah satu perusahaan yang telah menerapkan teknologi informasi dalam mendukung proses bisnisnya adalah PT. Genta Semar Mandiri.

Sebagai salah satu perusahaan besar, perusahaan ini telah menerapkan teknologi informasi dan komunikasi dalam rutinitasnya. Perusahaan ini telah menerapkan sistem informasi yang disebut kingdee. Kingdee merupakan sebuah program berbasis web yang merupakan pengembangan dari Web ERP yang mana fungsi utama dari program ini adalah pengelolaan barang dan kegiatan pergudangan. Namun demikian PT. Genta Semar Mandiri sendiri masih memiliki masalah dalam penggunaan sistem informasi. Sering terjadinya berbagai masalah/ insiden mengakibatkan proses bisnis kurang optimal pelaksanaannya, contoh insiden yang terjadi adalah aplikasi yang sering error pada bagian inventory di mana data yang ada beberapa kali tidak dapat diakses. Hal - hal ini perlu diperbaiki agar dapat memberikan efek yang lebih baik kepada perusahaan. Selama ini pada PT. Genta Semar Mandiri belum ada pengelolaan manajemen insiden dengan baik. Hal ini dikarenakan belum adanya divisi yang bertanggung jawab mengelola tata kelola insiden.

Beberapa framework yang berkaitan dengan manajemen layanan IT adalah ITIL Versi 3, ISO 2000, dan COBIT 5. Penelitian ini menggunakan ITIL versi 3 karena merupakan sebuah kerangka kerja yang sudah dirumuskan berdasarkan dari praktek terbaik pada perusahaanperusahaan yang menyediakan layanan terkemuka di dunia, sehingga ITSM lebih cocok menggunakan pendekatan ITIL (IT Infrastructure Library) [1] yang telah menjadi standar internasional sesungguhnya untuk IT Service Management. Fokus pada quality service dan best practice telah membuat kerangka kerja ITIL menjadi paling popular dan umum didalam perencanaan dan pengelolaan proses dan peran-peran serta aktivitas IT Service Management [2]. Melihat peran kerangka kerja ITIL, perusahaan dapat menggunakannya, baik secara keseluruhan atau sebagian, tergantung pada preferensi. ITIL menyediakan panduan tentang bagaimana menghubungkan proses dan kegiatan yang ada di departemen TI. Merujuk pada penjelasan mengenai ITIL, maka kerangka kerja ini dapat dijadikan salah satu solusi untuk membantu menunjang pengembangan inovasi yang ingin dilakukan oleh perusahaan untuk peningkatan performa pengelolaan layanan teknologi informasi.

Pada ITIL versi 3 memiliki 5 tingkatan proses Siklus hidup layanan TI, yaitu Service Strategy, Service Design, Service Transition, Service Operation, dan Continual Service Improvement [3]. Dalam penelitian ini model yang dikembangkan adalah untuk mendefinisikan fungsi layanan TI dan pedoman penyampaian layanan TI dengan menggunakan pendekatan service operation. Terdapat 9 proses-proses yang dicakup dalam Service Operation yaitu, Event Management, Incident Management, Problem Management, Request Fulfillment, Access Management, IT Operations Control, Application Management, Technical Management, Facilities Management [1].

Penelitian ini berfokus pada domain service operation dan sub domain incident management, karena solusi dari masalah perusahaan ini memiliki fokus pada kegiatan rutinitas layanan IT dalam perusahaan terutama pada bagian manajemen untuk insiden. Kelebihan dari metode ini adalah pelayanan yang sudah terbukti dan digunakan secara global. ITIL memberikan 
konsep umum dan istilah dalam serangkaian best practice terintegrasi yang berkembang untuk memenuhi kebutuhan pasar dalam siklusnya secara berkelanjutan dan dengan mengadopsi konsep yang sudah terbukti, penyedia layanan dapat dengan mudah memberikan layanan secara konsesten. Berdasarkan dari organisasi yang telah menerapkan ITIL dan penerapan tersebut dapat meningkatkan mutu pelayanan, yaitu PROACTER dan GAMBLE (pada tahun 1999 mulai menggunakan ITIL mampu mengurangi panggilan pada helpdesk sampai 10\%) dan CATERPILLAR (menggunakan ITIL pada tahun 2000, setelah menerapkan prinsip ITIL, nilai pencapaian waktu respon target untuk Incident Management naik dari $60 \%$ menjadi lebih dari 90\%) [4].

Dalam menerapkan manajemen insiden diharapkan perusahaan dapat mengembalikan layanan IT sehingga berfungsi lebih baik untuk mengembalikan layanan IT lebih baik diperlukan Standard Operating Procedure (SOP). Pada penelitian [5] menghasilkan Standard Operating Procedure (SOP) dan formulir yang dapat digunakan untuk mengelola berbagai insiden untuk manajemen layanan TI [6]. Oleh karena itu pembuatan pada dokumen SOP sangatlah penting [7], terutama dalam proses yang dilakukan oleh service desk untuk menjamin kualitas sistem, penyusunan SOP ini dilakukan berdasarkan pengamatan kondisi eksisiting berkaitan dengan pengelolan layanan TI untuk lingkup proses manajemen insiden dan mengembangkannya dengan proses berdasarkan framework ITIL versi 3.

\section{METODE PENELITIAN}

Semua metodologi pengumpulan data yang digunakan pada penelitian ini antara lain studi literature, wawancara serta obersvasi langsung pada PT. Genta Semar Mandiri.

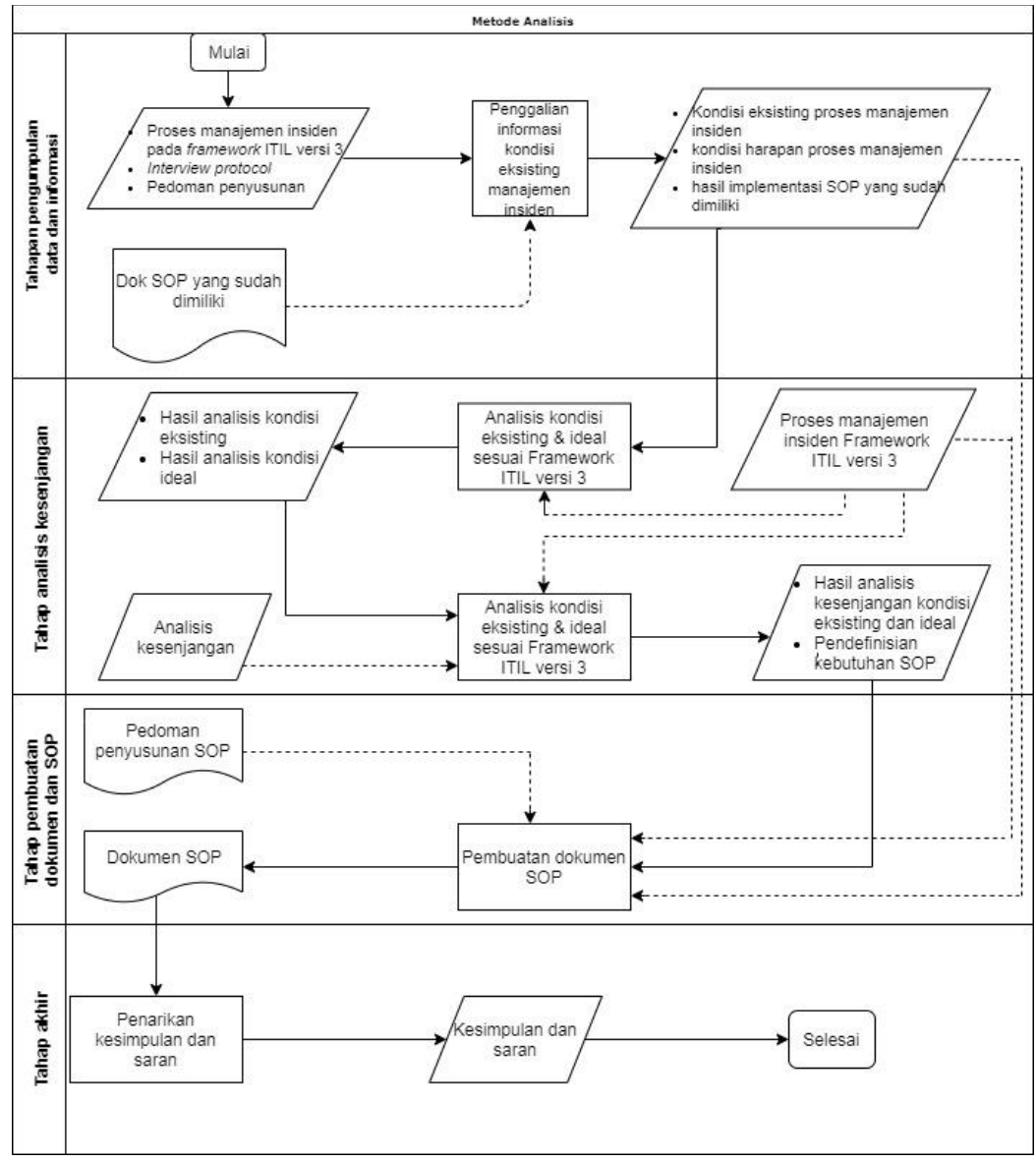

Gambar 1. Metode analisis 
Terdapat beberapa tahap metode analisis dalam ITIL versi 3 seperti pada gambar 1 diantaranya antara lain :

\subsection{Tahap pengumpulan data dan informasi}

Pengumpulan data dan informasi dilakukan dengan cara wawancara staff PT. Genta Semar Mandiri, observasi dan studi literatur mengenai penanganan insiden yang telah berjalan.

\subsection{Tahap analisis kesenjanan}

Melakukan aktifitas untuk menganlisis kondisi eksisting mengenai proses penanganan insiden, yang selanjutnya mengidentifikasi apakah terdapat kesenjangan yang terjadi antara kondisi eksisting dengan kondisi ideal yang diinginkan. Dengan mengidentifikasi mengenai kesenjangan yang terjadi antara kondisi eksisting dengan kondisi ideal dengan cara membandingkan proses penangan insiden. Proses atau bagian mana yang sudah memenuhi kondisi ideal dan bagianmana yang masih belum memenuhi, dan kemudian akan dihasilkan kesenjangan menurut framework ITIL versi 3. Kemudian mengidentifikasi perubahan yang dapat memberikan lauanan yang optimal kepada user, mengidentifikasi dampak dan solusinya.

\subsection{Tahap pembuatan SOP}

Pada tahapan ini dilakukan penyusunan dokumen SOP sesuai dengan hasil dari analisis kesenjangan yang telah dilakukan berdasarkan framework ITIL versi 3.

\subsection{Tahap akhir}

Kesimpulan dan saran sesuai dengan hasil penelitian yang dilakukan. Kesimpulan akan memberikan jawaban dari rumusan masalah dan tujuan penelitian, dan saran yang bisa dilakukan untuk PT. Genta Semar Mandiri atau untuk penelitian selanjutnya.

\section{HASIL DAN PEMBAHASAN}

Sumber Bagian ini menjelaskan mengenai analisis kesenjangan dari proses layanan insiden TI serta solusi yang dapat diberikan untuk memanajemen layanan inisiden dengan lebih baik sesuai dengn framework ITIL versi 3.

\subsection{Analisis Kesenjangan beserta solusi yang dapat dilakukan}

Berikut pada tabel 1 adalah pemetaan proses bisnis penanganan layanan insiden terkait dengan kondisi eksisting dan kondisi ideal pada proses manajemen insiden.

Tabel 1. Identifikasi kesenjangan

\begin{tabular}{|c|c|c|c|}
\hline Aktifitas & Kondisi Eksisting & Kondisi Ideal & Kesenjangan \\
\hline $\begin{array}{c}\text { Incident } \\
\text { identificat } \\
\text { ion }\end{array}$ & $\begin{array}{l}\text { Pelaporan adanya } \\
\text { insiden sistem informasi } \\
\text { inventory secara lisan ke } \\
\text { accounting yang } \\
\text { selanjutnya akan } \\
\text { diserahkan pada bagian } \\
\text { Engineering dari vendor } \\
\text { luar melalui email atau } \\
\text { pesan }\end{array}$ & $\begin{array}{l}\text { 1. Pelaporan masalah sistem } \\
\text { informasi inventory diterima } \\
\text { oleh service desk } \\
\text { 2. Tanggung jawab dalam } \\
\text { mengelola insiden sistem } \\
\text { informasi inventory adalah } \\
\text { tanggung jawab dari service } \\
\text { desk }\end{array}$ & $\begin{array}{l}\text { Belum adanya staff } \\
\text { yang mempunyai } \\
\text { tanggung jawab dalam } \\
\text { menerima pelaporan. } \\
\text { Sehingga di perlukan } \\
\text { usulan penambahan } \\
\text { staff yang khusus untuk } \\
\text { menerima pelaporan } \\
\text { insiden sistem } \\
\text { informasi inventory. }\end{array}$ \\
\hline
\end{tabular}




\begin{tabular}{|c|c|c|c|}
\hline Aktifitas & Kondisi Eksisting & Kondisi Ideal & Kesenjangan \\
\hline $\begin{array}{l}\text { Incident } \\
\text { Logging }\end{array}$ & 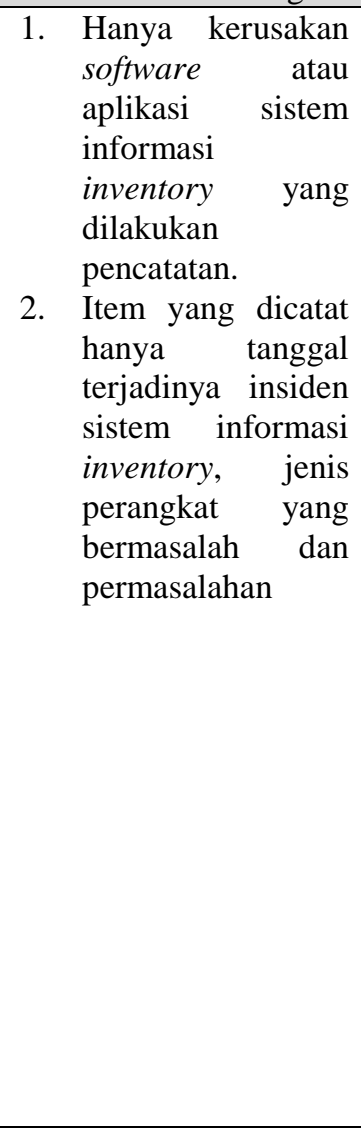 & $\begin{array}{l}\text { 1. Semua perangkat yang } \\
\text { mengalami permasalahan } \\
\text { harus dicatat tidak ada } \\
\text { pengecualian. } \\
\text { 2. Semua aktivitas penanganan } \\
\text { insiden juga dilakukan } \\
\text { pencatatan. } \\
\text { 3. Item yang perlu dicatat antara } \\
\text { lain : } \\
\text { a. Nomor ID } \\
\text { b. Kategori insiden } \\
\text { c. Urgensi insiden } \\
\text { d. Dampak insiden } \\
\text { e. Prioritas insiden } \\
\text { f. Wakti pencatatan insiden } \\
\text { g. Pihak pencatat insiden } \\
\text { h. Media notifikasi } \\
\text { i. Informasi user } \\
\text { j. Deskripsi masalah } \\
\text { k. Status Penanganan Masalah } \\
\text { l. Mengalokasikan insiden ke } \\
\text { magian penanganan } \\
\text { m. Masalah terkait } \\
\text { n. Kegiatan yang dilakukan } \\
\text { o. Wntuk penyelesaian masalah } \\
\text { p. Kategori penutupan masalah } \\
\text { q. Waktu penutupan insiden }\end{array}$ & $\begin{array}{l}\text { 1. Hanya masalah } \\
\text { aplikasi sistem } \\
\text { informasi inventory } \\
\text { saja yang dicatat } \\
\text { sehingga masalah } \\
\text { hardware dan data } \\
\text { tidak dilakukan } \\
\text { proses pencatatan. } \\
\text { 2. Pencatatan tentang } \\
\text { insiden tidak } \\
\text { lengkap dan tidak } \\
\text { adanya proses } \\
\text { dokumentasi } \\
\text { penyelesaian } \\
\text { insiden yang terjadi } \\
\text { di gudang terkait } \\
\text { sistem informasi } \\
\text { inventory. }\end{array}$ \\
\hline $\begin{array}{l}\text { Incident } \\
\text { Categoriz } \\
\text { ation }\end{array}$ & $\begin{array}{l}\text { Proses pengkategorian } \\
\text { insiden sistem informasi } \\
\text { inventory dilakukan } \\
\text { oleh bagian accounting. } \\
\text { Insiden akan } \\
\text { dikategorisasikan } \\
\text { menjadi masalah } \\
\text { hardware, software, } \\
\text { atau data. }\end{array}$ & $\begin{array}{l}\text { Kategorisasi insiden harus sesuai } \\
\text { dengan kebutuhan perusahaan } \\
\text { seperti jenis layanan, komponen. } \\
\text { Misalnya jika insiden yang terjadi } \\
\text { adalah berkaitan dengan program } \\
\text { aplikasi sistem informasi } \\
\text { inventory maka akan } \\
\text { dikategorisasikan sebagai insiden } \\
\text { software. Dan hendaknya proses } \\
\text { kategorisasi dilakukan sespesifik } \\
\text { mungkin untuk mempermudah } \\
\text { proses penyelesaian insiden pada } \\
\text { sistem informasi inventory. }\end{array}$ & $\begin{array}{lr}\text { 1. Belum } & \text { adanya } \\
\text { standar } & \text { yang } \\
\text { ditetapkan } & \text { secara } \\
\text { formal } & \text { terkait } \\
\text { kategorisasi } & \text { insiden } \\
\text { yang terjadi di sistem } \\
\text { informasi inventory. } \\
\text { 2. Proses } \\
\text { pengkategorian } \\
\text { insiden pada sistem } \\
\text { informasi inventory } \\
\text { belum dilakukan } \\
\text { dengan spesifik. }\end{array}$ \\
\hline $\begin{array}{l}\text { Incident } \\
\text { Prioritazi } \\
\quad \text { on }\end{array}$ & $\begin{array}{l}\text { Insiden yang pertama } \\
\text { terjadi, itulah yang akan } \\
\text { lebih dulu ditangani. }\end{array}$ & $\begin{array}{l}\text { 1. Prioritas penanganan insiden } \\
\text { pada sistem informasi } \\
\text { inventory ditentukan } \\
\text { berdasarkan besarnya dampak } \\
\text { yang akan terjadi di divisi } \\
\text { gudang atau divisi lain dan } \\
\text { urgensi insiden yang terjadi } \\
\text { sehingga dapat mengetahui } \\
\text { insiden mana yang perlu } \\
\text { dilakukan penanganan terlebih } \\
\text { dahulu. } \\
\text { 2. Adanya target waktu ideal } \\
\text { penanganan layanan } \\
\text { berdasarkan framework ITIL } \\
\text { versi 3. }\end{array}$ & 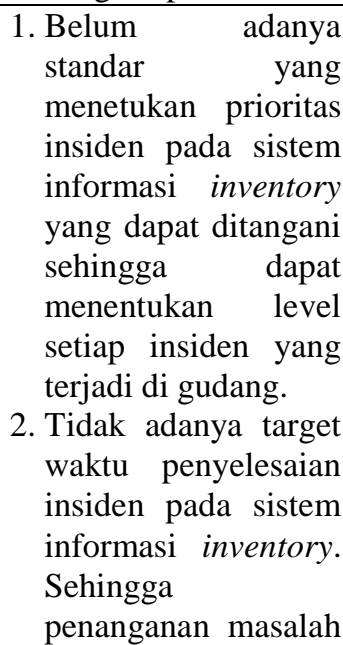 \\
\hline
\end{tabular}




\begin{tabular}{|c|c|c|c|}
\hline Aktifitas & Kondisi Eksisting & Kondisi Ideal & Kesenjangan \\
\hline & & & $\begin{array}{l}\text { tergantung pada staff } \\
\text { vendor luar yang } \\
\text { menangani. }\end{array}$ \\
\hline $\begin{array}{c}\text { Initial } \\
\text { Diagnosis }\end{array}$ & $\begin{array}{lr}\text { 1. } & \begin{array}{l}\text { Manager } \\
\text { akan melaporkan } \\
\text { pada bagian } \\
\text { accouting tentang } \\
\text { masalah yang terjadi. }\end{array} \\
\text { 2. } & \begin{array}{l}\text { Bagian Accounting } \\
\text { akan melakukan }\end{array} \\
\text { kategorisasi masalah } \\
\text { kemudian melakukan } \\
\text { pelaporan pada } \\
\text { bagian Engineering. } \\
\text { 3. Bagian Engineering } \\
\text { akan menentukan } \\
\text { staff yang akan } \\
\text { menangani masalah. } \\
\text { 4. Bila memungkinkan } \\
\text { staff Engineering } \\
\text { akan langsung } \\
\text { menangani masalah } \\
\text { yang di laporkan. }\end{array}$ & $\begin{array}{l}\text { Service desk akan mengumpulan } \\
\text { semua informasi yang ada } \\
\text { kaitannya dengan insiden pada } \\
\text { sistem informasi inventory yang } \\
\text { terjadi dan berupaya untuk } \\
\text { melakukan penanganan terlebih } \\
\text { dulu sebelum diteruskan ke } \\
\text { manajemen insiden pada vendor } \\
\text { luar atau menejemen level } \\
\text { support. }\end{array}$ & 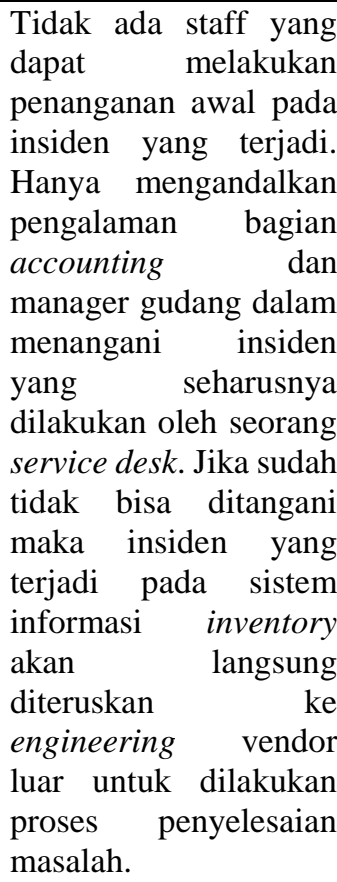 \\
\hline
\end{tabular}

Belum adanya proses eskalasi yang dilakukan sehingga belum ada prosedur yang mengatur tentang eskalasi insiden.

Functiona Jika staff Engineering $l$ tidak dapat melakukan Excalatio penanganan insiden maka permasalahan akan dilemparkan ke pihak ketiga secara eksternal.
Service desk akan melakukan proses eksalasi indisden jika tidak dapat ditangani lebih awal oleh dirinya yaitu :

1. Level fungsional

Proses eskalasi dilakukan oleh tim teknis untuk penanganan lebih lanjut.

2. Level Hirearki

Proses eskalasi dilakukan oleh tim manajemen organisasi untuk proses penanganan lebih lanjut jika tim teknis tidak dapat menyelesaian permasalahan yang terjadi.

\section{Proses}

pengidentifikasian masalah akan dilakukan oleh staff Engineering yang telah ditunjuk untuk menyelesaikan

Investigati masalah. Namun belum on and

Diagnosis $\begin{array}{lr}\text { dilakukan } & \text { proses } \\ \text { dokumentasi } & \text { saat }\end{array}$ melakukan identifikasi insiden karena penyelesaian dilakukan oleh vendor luar.

Investigasi akan dilakuan untuk menetukan sumber masalah dari insiden yang terjadi yang mencakup aktivitas-aktivitas :

1. Menetapkan masalah yang terjadi

2. Mengidentifikasi urutan atau kronologi kejadian

3. Memastikan dampak yang dapat terjadi

4. Mengidentifikas masalah yang memicu adanya kendala/insiden

5. Mencari data dengan menganalisi daftar insiden
Belum adanya proses eskalasi yang dilakukan sehingga diperlukan informasi atau data alur eskalasi insiden pada sistem informasi inventory berdasarkan framework ITIL versi 3 sehingga dapat mengetahui kepada siapa layanan insiden yang terjadi pada divisi gudang dapat dieskalasikan.

Karena tidak adanya pendokumentasian tentang riwayat insiden sebelumnya, sehingga bagian accounting/gudang dam teknisi dari vendor luar menyelesaikan insiden yang terjadi sesuai dengan kemampuannya .

Solusi yang diberikan kurang maksimal

karena tidak tahu riwayat insiden yang 


\begin{tabular}{|c|c|c|c|}
\hline Aktifitas & Kondisi Eksisting & Kondisi Ideal & Kesenjangan \\
\hline & & $\begin{array}{l}\text { sistem informasi inventory } \\
\text { yang terjadi sebelumnya. }\end{array}$ & $\begin{array}{l}\text { terjadi sebelumnya } \\
\text { pada divisi gudang. }\end{array}$ \\
\hline $\begin{array}{c}\text { Resolution } \\
\text { and } \\
\text { Discovery }\end{array}$ & $\begin{array}{lr}\text { Setelah dilakukan } \\
\text { penanganan, } \\
\text { Engineering } \\
\text { menunjukkan akan } \\
\text { langsung pada divisi } \\
\text { gudang tentang masalah } \\
\text { yang terjadi dan cara } \\
\text { penanganan. Namun, } \\
\text { pada proses ini tidak } \\
\text { dilakukan } \\
\text { pendokumentasian oleh } \\
\text { teknisi yang menangani } \\
\text { insiden pada sistem } \\
\text { informasi inventory. }\end{array}$ & $\begin{array}{l}\text { 1. Dilakukan proses implementasi } \\
\text { penyelesaian insiden yang } \\
\text { terjadi pada sistem informasi } \\
\text { inventory dengan baik. } \\
\text { 2. Memastikan prosedur yang } \\
\text { dilakukan dapat menyelesaikan } \\
\text { insiden yang terjadi dan } \\
\text { mengembalikan kondisi layanan } \\
\text { sistem informasi inventory } \\
\text { secara maksimal. }\end{array}$ & $\begin{array}{l}\text { Belum sesuai dengan } \\
\text { kondisi } \\
\text { berdasarkan framework } \\
\text { ITIL versi 3, karena } \\
\text { belum dilakukan } \\
\text { pendokumentasian } \\
\text { penyelesaian insiden } \\
\text { yang terjadi pada } \\
\text { sistem informasi } \\
\text { inventory sebagai } \\
\text { dokumen. }\end{array}$ \\
\hline $\begin{array}{l}\text { Incident } \\
\text { Closure }\end{array}$ & $\begin{array}{l}\text { Tidak ada pengecekan } \\
\text { ulang tentang masalah } \\
\text { yang terjadi pada sistem } \\
\text { informasi inventory, dan } \\
\text { tidak ada } \\
\text { pendokumentasian } \\
\text { penyelesaian masalah. } \\
\text { Staff Engineering hanya } \\
\text { mengkonfirmasi pada } \\
\text { divisi gudang tentang } \\
\text { solusi yang telah } \\
\text { dilakukan pada insiden } \\
\text { terkait sistem informasi } \\
\text { inventory. }\end{array}$ & $\begin{array}{l}\text { 1. Service desk yang akan } \\
\text { menginformasikan kepada } \\
\text { pihak terkait jika insiden telah } \\
\text { diselesaikan. } \\
\text { 2. Service desk perlu kembali } \\
\text { memastikan data pencatatan } \\
\text { telah lengkap dan sesuai } \\
\text { dengan penanganan insiden } \\
\text { yang terjadi. } \\
\text { 3. Dilakukan pengecekan } \\
\text { kembali atas penyelesaian } \\
\text { insiden yang terjadi sehingga } \\
\text { terjadi kepuasan pengguna. }\end{array}$ & $\begin{array}{l}\text { 1. Tidak dilakukan } \\
\text { pencatatan dan } \\
\text { pengdokumentasia } \\
\mathrm{n} \text { tentang } \\
\text { penyelesaian } \\
\text { insiden pada sistem } \\
\text { informasi } \\
\text { inventory. } \\
\text { 2. Tidak dilakukan } \\
\text { pengecekan } \\
\text { kembali } \\
\text { penyelesaian } \\
\text { insiden yang telah } \\
\text { diselesaikan pada } \\
\text { sistem informasi } \\
\text { inventory. }\end{array}$ \\
\hline
\end{tabular}

\subsection{Solusi yang dibuat}

Solusi yang diambil harus dapat mempengaruhi aktivitas bisnis pada perusahaan, dengan menambah aktivitas maupun mengurangi aktivitas yang sudah berjalan. Keputusan pembuatan solusi harus sesuai dengan acuan proses bisnis yang ideal sesuai dengan framework ITILversi 3 yang dapat dilihat dari tabel 2 berikut ini:

Tabel 2. Identifikasi solusi

\begin{tabular}{cllll}
\hline Aktivitas & \multicolumn{2}{c}{ Perubahan } & \multicolumn{2}{c}{ Solusi } \\
\hline & Penambahan sebuah posisi staff & Efektifitas penanganan & Penambahan \\
& sebagai service desk untuk insiden agar terpusat serta & karyawan sebagai \\
Incident & menampung segala informasi & mempermudah proses & service desk, teknisi \\
identification & terjadinya insiden di gudang & penanganan insiden & IT, dan supervisor \\
& terkait sistem informasi & sistem & informasi & teknisi IT. \\
& inventory secara terpusat. & inventory & & \\
\hline
\end{tabular}




\begin{tabular}{|c|c|c|c|}
\hline Aktivitas & Perubahan & Alasan & Solusi \\
\hline $\begin{array}{l}\text { Incident } \\
\text { Logging }\end{array}$ & $\begin{array}{l}\text { Pencatataan seluruh insiden yang } \\
\text { terjadi pada gudang terkait } \\
\text { sistem informasi inventory } \\
\text { dengan rinci sesuai dengan } \\
\text { kategorinya. Tidak hanya insiden } \\
\text { yang berkaitan dengan software } \\
\text { atau program aplikasi sistem } \\
\text { informasi inventory saja namun } \\
\text { segala jenis insiden yang terjadi } \\
\text { di gudang terkait sistem } \\
\text { informasi inventory. } \\
\text { Dilakukan pencatatan tentang } \\
\text { insiden secara lengkap dan } \\
\text { adanya proses dokumentasi } \\
\text { terjadinya insiden. }\end{array}$ & $\begin{array}{l}\text { Dokumentasi/pencatatata } \\
\mathrm{n} \text { yang rinci pada seluruh } \\
\text { insiden mempermudah } \\
\text { proses penanganan } \\
\text { insiden selanjutnya. } \\
\text { Dokumentasi merupakan } \\
\text { bukti konkrit terjadinya } \\
\text { insiden. }\end{array}$ & $\begin{array}{l}\text { Pencatatan } \\
\text { pelaporan seluruh } \\
\text { aktivitas insiden } \\
\text { pada seluruh insiden } \\
\text { yang terjadi di } \\
\text { gudang terkait } \\
\text { sistem informasi } \\
\text { inventory. } \\
\text { Mempermudah } \\
\text { pencarian riwayat } \\
\text { insiden yang pernah } \\
\text { terjadi untuk proses } \\
\text { penanganan insiden } \\
\text { pada sistem } \\
\text { informasi inventory. }\end{array}$ \\
\hline $\begin{array}{c}\text { Incident } \\
\text { Categorizati } \\
\text { on }\end{array}$ & $\begin{array}{l}\text { Dibuatnya standar yang } \\
\text { ditetapkan secara formal terkait } \\
\text { kategorisasi insiden di gudang } \\
\text { terkait sistem informasi } \\
\text { inventory. } \\
\text { Proses pengkategorian insiden } \\
\text { pada sistem informasi inventory } \\
\text { dilakukan dengan spesifik. }\end{array}$ & $\begin{array}{l}\text { Adanya standar } \\
\text { kategorisasi } \\
\text { mempermudah service } \\
\text { desk dalam menentukan } \\
\text { kategorisasi insiden yang } \\
\text { terjadi. } \\
\text { Pencatatan kategorisasi } \\
\text { secara spesifik berguna } \\
\text { pada proses penanganan } \\
\text { agar insiden dapat } \\
\text { ditangani dengan cepat } \\
\text { dan tepat. }\end{array}$ & $\begin{array}{l}\text { Mempermudah } \\
\text { proses pemberian } \\
\text { kategori layanan } \\
\text { insiden dan } \\
\text { mempermudah } \\
\text { penangan insiden } \\
\text { jika insiden sudah } \\
\text { dipisahkan menurut } \\
\text { kategorinya. }\end{array}$ \\
\hline $\begin{array}{c}\text { Incident } \\
\text { Prioritazion }\end{array}$ & 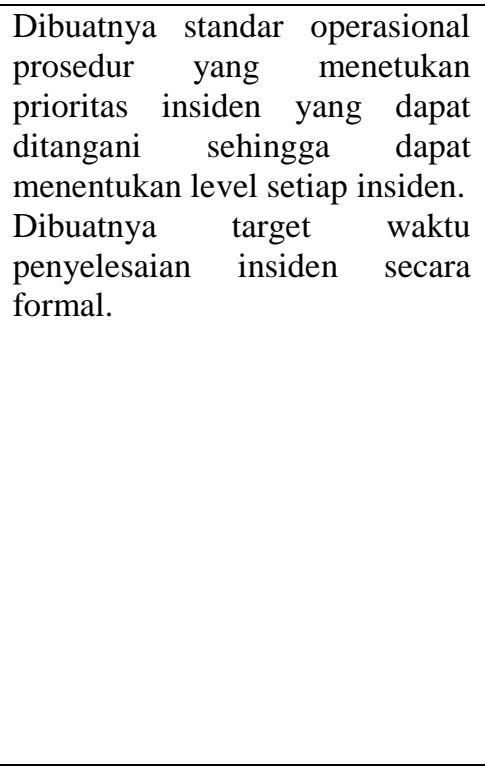 & $\begin{array}{l}\text { SOP mempermudah } \\
\text { service desk untuk } \\
\text { menentukan prioritas } \\
\text { insiden yang terjadi. } \\
\text { Sehingga service desk } \\
\text { mempunyai acuan dalam } \\
\text { penentuan prioritas } \\
\text { insiden. } \\
\text { Target waktu digunakan } \\
\text { sebagai r deadline } \\
\text { pengerjaan insiden } \\
\text { sehingga teknisi memiliki } \\
\text { batas waktu dalam } \\
\text { penyelesaian insiden, dan } \\
\text { kendala tidak dibiarkan } \\
\text { berlarut-larut yang dapat } \\
\text { menyebabkan } \\
\text { terganggunya } \\
\text { bisnis. }\end{array}$ & \begin{tabular}{lr}
\multicolumn{2}{l}{ Mempermudah } \\
dalam penentuan \\
prioritas layanan \\
insiden agar teknisi \\
dapat melakukan \\
layanan insiden \\
dengan tepat waktu.
\end{tabular} \\
\hline $\begin{array}{c}\text { Initial } \\
\text { Diagnosis }\end{array}$ & $\begin{array}{l}\text { Menyediakan staff yang dapat } \\
\text { melakukan penanganan awal } \\
\text { pada insiden yang terjadi yaitu } \\
\text { service desk. Insiden akan } \\
\text { langsung diteruskan ke } \\
\text { engineering untuk dilakukan } \\
\text { proses penyelesaian masalah. }\end{array}$ & $\begin{array}{l}\text { Staff/ service desk mampu } \\
\text { memberikan penanganan } \\
\text { awal sehingga jika insiden } \\
\text { tidak terlalu rumit dapat } \\
\text { diselesaikan tanpa } \\
\text { memanggil teknisi yang } \\
\text { memakan waktu yang } \\
\text { lebih lama. }\end{array}$ & $\begin{array}{l}\text { Adanya aktivitas } \\
\text { awal untuk } \\
\text { mendiagnosis } \\
\text { insiden sehingga } \\
\text { service desk dapat } \\
\text { menangani jika bisa } \\
\text { ditangani sendiri } \\
\text { sebelum dialihkan } \\
\text { pada teknisi. }\end{array}$ \\
\hline
\end{tabular}




\begin{tabular}{|c|c|c|c|}
\hline Aktivitas & Perubahan & Alasan & Solusi \\
\hline & & & $\begin{array}{l}\text { Terdapat perubahan } \\
\text { status penanganan } \\
\text { insiden }\end{array}$ \\
\hline $\begin{array}{l}\text { Functional } \\
\text { Excalation }\end{array}$ & $\begin{array}{l}\text { Dibuatnya Standar Operasional } \\
\text { Prosedur terkait proses eskalasi } \\
\text { yang dilakukan sehingga } \\
\text { diperlukan informasi atau data } \\
\text { alur eskalasi insiden berdasarkan } \\
\text { framework ITIL versi } 3 \\
\text { Ditetapkannya penanggung } \\
\text { jawab sehingga dapat } \\
\text { mengetahui kepada siapa } \\
\text { layanan insiden } \\
\text { dieskalasikan. }\end{array}$ & $\begin{array}{l}\text { SOP dibuat } \\
\text { memberikan standarisasi } \\
\text { dalam proses eskalasi } \\
\text { sehingga proses eskalasi } \\
\text { berjalan } \\
\text { sistematis. } \\
\text { Penetapan penanggung } \\
\text { jawab berguna agar divisi } \\
\text { lain mengetahui siapa } \\
\text { yang bertangung jawab } \\
\text { pada proses penanganan } \\
\text { insiden. }\end{array}$ & $\begin{array}{l}\text { Mempermudah } \\
\text { dalam pengambilan } \\
\text { keputusan dalam } \\
\text { proses eskalasi . } \\
\text { Mengetahui pada } \\
\text { siapa insiden } \\
\text { seharusnya } \\
\text { dilakukan eskalasi. } \\
\text { Penanganan insiden } \\
\text { selalu terupdate. }\end{array}$ \\
\hline $\begin{array}{l}\text { Investigation } \\
\text { and } \\
\text { Diagnosis }\end{array}$ & $\begin{array}{l}\text { Setiap penanganan dilakukan } \\
\text { pencatatan dan } \\
\text { pendokumentasian untuk data } \\
\text { sebagai dasar atau acuan dalam } \\
\text { penanganan insiden di masa yang } \\
\text { akan datang. } \\
\text { Sebelum melakukan penanganan } \\
\text { perlu mengetahui riwayat insiden } \\
\text { yang pernah terjadi } \\
\text { menggunakan data yang sudah } \\
\text { dikumpulkan. }\end{array}$ & $\begin{array}{lr}\text { Pencatatan } & \text { diperlukan } \\
\text { sebagai } & \text { dokumentasi } \\
\text { untuk } & \text { mempermudah } \\
\text { proses } & \text { penanganan } \\
\text { insiden di masa yang akan } \\
\text { datang. }\end{array}$ & \begin{tabular}{lr}
\multicolumn{2}{l}{ Mempermudah } \\
dalam diagnosis \\
insiden dan \\
keputusan dalam \\
penanganan insiden \\
dari riwayat \\
pencatatan insiden \\
yang pernah terjadi. \\
Mempermudah \\
dalam penanganan \\
insiden yang terjadi \\
dari riwayat \\
pencatatan dan \\
dokumentasi \\
insiden.
\end{tabular} \\
\hline $\begin{array}{l}\text { Resolution } \\
\quad \text { and } \\
\text { Discovery }\end{array}$ & $\begin{array}{l}\text { Dilakukan pendokumentasian } \\
\text { penyelesaian insiden yang terjadi } \\
\text { sebagai data. }\end{array}$ & $\begin{array}{l}\text { Dokumentasi digunakan } \\
\text { sebagai bukti penanganan } \\
\text { insiden, dan data tersebut } \\
\text { membantu proses } \\
\text { penanganan insiden yang } \\
\text { akan terjadi di masa } \\
\text { datang sebagai referensi. }\end{array}$ & $\begin{array}{l}\text { Adanya aktivitas } \\
\text { pencatatan secara } \\
\text { rinci tentang proses } \\
\text { penyelesaian } \\
\text { insiden yang terjadi. }\end{array}$ \\
\hline $\begin{array}{l}\text { Incident } \\
\text { Closure }\end{array}$ & $\begin{array}{l}\text { Dilakukan pencatatan dan } \\
\text { pengdokumentasian tentang } \\
\text { penyelesaian insiden. } \\
\text { Dilakukan pengecekan kembali } \\
\text { penyelesaian insiden yang telah } \\
\text { diselesaikan. }\end{array}$ & $\begin{array}{lr}\text { Pencatatan } & \text { digunakan } \\
\text { sebagai } & \\
\text { dokumentasi/bukti proses } \\
\text { penaganan } \\
\text { sebagai inisden } \\
\text { pertanggung jawaban } \\
\text { teknisi telah selesai } \\
\text { menangani insiden. } \\
\text { Pengecekan dilakukan } \\
\text { agar user dapat } \\
\text { mengetahui hasil dari } \\
\text { proses penyelesaian } \\
\text { insiden yang terjadi. }\end{array}$ & $\begin{array}{l}\text { Adanya aktivitas } \\
\text { pencatatan dan } \\
\text { dokumentasi } \\
\text { penutupan insiden. } \\
\text { Adanya aktivitas } \\
\text { pengecekan } \\
\text { insiden setelah } \\
\text { dikerjakan terhadap } \\
\text { pihak yang terkait. }\end{array}$ \\
\hline
\end{tabular}

Dan berikut pada tabel 3 adalah beberapa SOP yang dibuat sebagai bentuk pelaksanaan solusi dari manajemen layana insiden: 
Tabel 3.SOP yang diusulkan

\begin{tabular}{ccl}
\hline \multicolumn{1}{c}{ Nomor SOP } & \multicolumn{1}{c}{ Nama SOP } & \multicolumn{1}{c}{ Deskripsi SOP } \\
\hline SOP-Insiden-001 & SOP Penanganan Insiden & $\begin{array}{l}\text { SOP ini berisi tindakan dalam menangani insiden } \\
\text { yang terjadi dan dapat diselesaikan oleh service } \\
\text { desk. }\end{array}$ \\
SOP-Insiden-002 & SOP Eskalasi Insiden & $\begin{array}{l}\text { SOP ini berisi tentang aktivitas eskalasi terhadap } \\
\text { insiden yang terjadi }\end{array}$ \\
SOP-Insiden-003 & SOP Penutupan Insiden & $\begin{array}{l}\text { SOP ini berisi tentang aktivitas untuk menutup } \\
\text { insiden yang sudah diselesaikan. } \\
\text { SOP ini berisi kegiatan pencatatan rekapitulasi } \\
\text { Seluruh insiden yang telah masuk. }\end{array}$ \\
\hline
\end{tabular}

\section{KESIMPULAN}

Semua Berdasarkan hasil penelitian dan pembahasan yang sudah dipaparkan sebelumnya tentang manajemen insiden terhadap sistem informasi inventory menggunakan framework ITIL versi 3, maka dapat diambil beberapa kesimpulan bahwa terdapat beberapa kesenjangan yang ditemukan antara lain tidak ada divisi yang secara khusus yang menangani insiden pada layanan TI, tidak adanya SOP dan dokumentasi yang jelas tentang proses penanganan insiden TI, serta tidak adanya standar target waktu penyelesaian insiden TI. Sehingga mengakibatkan manajemen layanan TI terganggu. Setelah mengetahui kesenjangan yang terjadi dilakukan perubahanperubahan yang diperlukan sesuai dengan framework ITIL versi 3 sehingga didapatkan beberapa perubahan yang dibuat antara lain membuat sebuah divisi IT yang khusus menanganani insiden IT khususnya pada sistem informasi inventory, membuat SOP dari pelaporan insiden, penanganan, hingga penutupan insiden dan membuat formulir terkait formulir pelaporan insiden, formulir pencatatan insiden, formulir eskalasi insiden, formulir penutupan insiden, formulir survey, serta formulir rekapitulasi data insiden.

\section{SARAN}

Adapun saran yang dapat diberikan untuk pengembangan lebih lanjut yaitu dengan mempermudah proses penanganan insiden diperlukan sebuah aplikasi yang terintegrasi yang dapat dirancang pada penelitian berikutnya. Penelitian ini perlu dikembangkan lebih lanjut mengenai implementasi IT Service Operation berdasarkan framework ITIL V3, apabila fasilitas infrastruktur dan aplikasi layanan TI di PT. Genta Semar Mandiri bagian gudang telah dibangun dan dikelola dengan baik. Selanjutnya dapat juga dilakukan pada domain layanan TI baru supaya hasil lebih terintegrasi dengan domain yang sudah dibahas pada penelitian ini.

\section{DAFTAR PUSTAKA}

[1] T. D. Susanto, sukses mengelola layanan teknologi informasi \& kiat lulus ujian sertifikasi itil foundation penulis tony d. susanto, ph.d., itil, cobit. Surabaya: AISINDO, 2017.

[2] R. Pereira and M. M. Da Silva, "ITIL maturity model," in Proceedings of the 5th Iberian Conference on Information Systems and Technologies, CISTI 2010, 2010.

[3] L. A. K. Wardani, M. Murahartawaty, and L. Ramadani, "Perancangan Tata Kelola Layanan Teknologi Informasi Menggunakan ITIL versi 3 Domain Service Transition Dan Service Operation Di Pemerintah Kota Bandung," J. Inf. Syst. Eng. Bus. Intell., vol. 2, no. 2, p. 81, 2016, doi: 10.20473/jisebi.2.2.81-87.

[4] E. Pink, "The Benefits of ITIL," 2008. 
[5] A. Rachmi, T. D. Susanto, and A. Herdiyanti, "Pembuatan Standard Operating Procedure (SOP) Service Desk Berdasarkan Kerangka Kerja ITIL V3 dengan Menggunakan Metode Analisis Gap Layanan ( Studi Kasus : PT XZY Tangerang)," J. Tek. Pomits, vol. 3, no. 2, pp. 175-180, 2014.

[6] A. H. B.C Hidayanto, A.N Ragiltya, "pembuatan standard operating procedure perawatan sistem informasi manajemen institut teknologi sepuluh september," vol. 07, pp. 27-46, 2017.

[7] J. D. Santosa, "Lebih Memahami SOP (Standard Operation Procedure)," in Lebih Memahami SOP (Standard Operation Procedure), Surabaya: Kata Pena, 2014. 